Egypt. J. of Nutrition and Health Vol. 16 No. 1 January (2021)

\title{
Potential Protective Effects of Plantago major Extracts against Indomethacin-Induced Gastric Ulcer in Rats
}

\author{
Eman M. Ragheb ${ }^{1, *}$, Eman S. Ibrahem ${ }^{1}$ and Rasha A. Shalaby ${ }^{1}$ \\ ${ }^{1}$ Regional Center for Food and Feed, Agricultural Research Center, Giza, Egypt. \\ ${ }^{*}$ Corresponding author
}

\begin{abstract}
Globally, gastric ulcer is one of the most serious diseases. Although, there are several antiulcer drugs, however most of them have adverse reactions. This research aims to investigate the protective effects of Plantago major extracts, water extract Plantago (WE) and ethanolic extract Plantago (EE) against indomethacin (IND)-induced gastric ulcer in rats.Also, to determine the active constituents and fatty acids content of Plantago major. Gastric ulcer was induced by a single oral dose of IND (30 mg/ kg). Plantago (WE) Plantago (EE) and Pantozol (Panto), a reference drug, were administered orally 14 days prior to IND ingestion. Plantago major contains high levels of total antioxidants, flavonoids, and phenols. Gas chromatography analysis showed a high percent of linoleic acid $(33.79 \%)$, oleic acid $(29.41 \%)$, and palmitic acid (19.25\%) in Plantago. Gross evaluation of gastric mucosal lesions showed that Plantago (WE) Plantago (EE) and Panto pretreatment reduced gastric lesions, diminished ulceration of surface epithelium, and maintained the normal histological structure of gastric mucosa induced by IND. Besides, significantly reduced ulcer index, total gastric acidity, gastric $\mathrm{pH}$, and serum oxidative stress compared with the IND group. Pretreatment with Plantago (WE), Plantago (EE) and Pantosignificantly increased gastric tissue content of nitric oxide (NO) and prostaglandin E2 (PGE2). In conclusion, pretreatment with Plantago (WE) Plantago (EE) showed a better ulcer healing capacity compared favorably well with Panto results, these results could be attributed to its high content of active antioxidant constituents.
\end{abstract}

Key words: Plantago major, Extract, Gastric ulcer, Indomethacin, Antioxidant

\section{Introduction}

Non-Steroidal Anti-inflammatory Drugs (NSAIDs.) are extensively used for their analgesic, anti-inflammatory and antipyretic properties. However, their frequent administration is usually associated with peptic ulcer induction (Lee et al., 2016). Indomethacin is an important member of the NSAIDs family. It is still extensively used in joint stiffness, arthritis, and in obstetrics to delay uterine contractions. In addition it is used in the neonatal unit to facilitate patent ductus arteriosus closure. However it provokes aggressive ulcerogenic potential in both animals and humans studies(Simon, 1993 and Saheedet al., 2015). Several researchers aimed to decrease damaging effects induced via indomethacin on gastrointestinal mucosa (Solimanet al., 2016). Indomethacin induces its gastrointestinal toxicity through several mechanisms such as an increase in gastric acid secretion; interfere with mucosal cell regeneration via inhibition of Prostaglandin E2 (PGE2) reduction of gastric nitric oxide level, and invasion of activated neutrophils, as well as induction of gastric cells apoptosis (Matsuiet al., 2011). 


\section{Eman M. et al}

There is a growing trend in the use of medicinal plant because of their medical effectiveness, low toxicity and many natural antioxidant agents derived from these plants (Ozaslanet al., 2007). Plantago major, belongs to the family Plantaginaceae, is an old medicinal plant that has been known for centuries (Samuelsen, 2000). The remarkable medicinal properties of Plantago major are due to it's the high content of phenols, flavonoids and tannin especially in its leaves (Mohamed et al., 2011).

Plantago major $\mathrm{L}$. is used as a remedy for various diseases in traditional medicine such as diseases related to the skin, respiratory organs, digestive organs, and reproduction. It has immune enhancing, wound-healing, hepatoprotective, anti-inflammatory, antigenotoxic, antioxidant and free radical scavenging effects (Samuelsen et al., 2000; Velasco-Lezamaet al., 2006 and Nazarizadehet al., 2013). It possesses anticancer and cytotoxic activity (Ozaslanet al., 2009). In addition, Plantagomajor methanolic extract displays anti ulcerogenic activity against $\mathrm{HCL}$ and absolute ethanolinduced gastric ulcer in rats (Abud et al., 2012).

The present study aimed to evaluate the potential protective action of water and ethanolic extracts of Plantago major against IND-induced gastric ulcer using Pantozol as a reference standard drug. Furthermore, the underlying mechanism will be explored focusing on the oxidative stress.

\section{Materials and Methods}

\section{Plant, drugs and chemicals}

Plantago major plant was obtained from Haraz for herbs and medicinal plants Company, Cairo, Egypt. Indomethacin (IND) from Hikma Pharmaceuticals PLC, Amman, Jordan, (provided as 25 mg/capsule). Pantozol® (Pantoprazole Sodium sesquihydrate, Takeda GmbH, Konstanz, Germanyas $20 \mathrm{mg}$ /tablet) from Pharmacy. Other chemicals and reagents were purchased from Sigma-Aldrich (St Louis, MO, USA).

\section{Animals}

Adult male rats Sprague Dawley $(n=50)$ weighing 190-210 g were purchased from Helwan Experimental Animals Farm, Giza, Egypt.

Analysis of Plantago major active constituents using Gas chromatography-mass spectroscopy (GC-MS)

The assay was performed utilizing a GC-MS (Agilent Technologies 7890A) connected to a mass-specific detector (MSD, Agilent 7000). Helium was the carrier gas. The recognition of constituents was carried out by comparing their mass spectra and retention time with the library of authentic compounds (NIST and WILEY) (Santana et al., 2013).

\section{Analysis of Plantago major antioxidant contents}

Plantago major total antioxidant content were assessed by the phosphor molybdenum method (Prieto et al., 1999), total phenols content was evaluated by the Folin-Ciocalteu method (Singleton et al., 1999), and total flavonoids was assessed by Dowd method using aluminum chloride colorimetric method as adapted by (Arvouet-Grand et al., 1994). 


\section{Egypt. J. of Nutrition and Health Vol. 16 No. 1 January (2021)}

\section{Analysis of total fatty acids contents in Plantago major}

Gas chromatography (GC) analysis of total fatty acids contents of Plantago major was determined by using methyl esters boron trifluoride method (AOAC, 2019). Plantago major powder was boiled with hydrochloric acid and then subjected to petroleum ether for fatty acid extraction. The oil is saponified with sodium hydroxide in methanol. The fatty acids are methylated with boron trifluoride in methanol, extracted with heptane, and determined on an autosampler GC with FID detector (PE Auto System XL) and Ezchrom integration system. Carrier gas (He); Ca. 25 Psi-air 450 ml/min- Hydrogen $45 \mathrm{ml}$ - split $100 \mathrm{ml} / \mathrm{min}$.

\section{Gastric ulcer induction}

Gastric ulcer was induced in all rats except for negative control group as described by Bhattacharya et al., (2007). The animals were fasted for $24 \mathrm{~h}$ before oral administration of a single dose of IND (30 mg/kg). Different degrees of gastric mucosal injuries were detected $4 \mathrm{~h}$ after IND administration.

\section{Experimental design}

Adult male albino rats $(n=50)$ weighing $190-210 \mathrm{~g}$ were used in this study.After one week on basal diet for acclimatization to the laboratory environment, the rats were randomized into the following 5 groups:

Group 1: (-ve control), rats received basal diet and distilled water orally.

Group 2: (IND), rats received basal diet and a single dose of IND (30 mg/kg) orally after 14 days.

Group 3: (Plantago WE + IND), rats received basal diet and Plantagomajor water extract (2 ml/day orally)daily for 14 days before IND.

Group 4: (Plantago EE + IND), rats received basal diet and Plantagomajor ethanol extract(2 ml/day orally)daily for 14 days before IND.

Group 5: (Panto + IND), rats received basal diet and Panto $(20 \mathrm{mg} / \mathrm{kg}))$ daily for 14 days before IND. After feeding the groups $(3,4,5)$ with the tested materials for 14 day, these rats were given orally a single dose of IND, after $4 \mathrm{~h}$ post IND administration, rats were sacrificed. The stomach was dissected out and cut along its greater curvature, then its content was evacuated into a centrifuge tube, diluted with distilled water and centrifuged at $12000 \mathrm{~g}$ for $10 \mathrm{~min}$. Gastric $\mathrm{pH}$ and total gastric acidity were detected in the supernatant. Cleaned stomach was preserved in formalin solution at $10 \%$ and processed for macroscopic examination and histopathological examination. Blood samples were collected, serum samples were separated and kept frozen until used for biochemical determination.

\section{Determination of gastric $\mathrm{pH}$}

The gastric juice was collected by a needle after tying the neck and the end of the stomach. Gastric juice $(1 \mathrm{ml})$ was diluted by distilled water $(1 \mathrm{ml})$ in an aliquot to measure $\mathrm{pH}$ using $\mathrm{pH}$ meter (Dashputre and Naikwade, 2011).

\section{Determination of total gastric acidity}

Gastric fluid supernatant $(1 \mathrm{ml})$ was diluted in a conical flask by distilled water $(1 \mathrm{ml})$. Phenolphthalein indicator (2 drops) was added, then the mixture was titrated with $0.01 \mathrm{~N} \mathrm{NaOH}$ till detection of a permanent pink color. The volume of $0.01 \mathrm{~N} \mathrm{NaOH}(\mathrm{V} \mathrm{NaOH})$ consumed was recorded. The total acidity (mEq/L) was calculated (Dashputre and Naikwade, 2011).

Acidity $=\mathrm{V} \mathrm{NaOH} \times \mathrm{N} \times 100$

Where $\mathrm{N}$ is normality 


\section{Eman M. et al}

\section{Quantification of ulcer index and percentage inhibition of ulceration}

Image Pro Express analyzer computer system was used to quantify the gastric ulcer index. The sum of gastric ulcer areas of all lesions for each stomach was used in the calculation of the ulcer area $\left(\mathrm{mm}^{2}\right)$. The total area of mucosa and the total area of ulcers area were calculated. Then, ulcer index and percentage inhibition of ulceration were calculated according to Meleseet al. (2011) using the following equations:

Ulcer index $(\mathbf{U I})=$ Total area of mucosal ulcers $/$ Total mucosal area

$\%$ Inhibition of ulceration= UI (IND group) - UI (test group) / UI (IND group) $\times 100$

\section{Determination of serum antioxidant biomarkers}

Oxidative stress biomarkers (malondialdehyde (MDA), superoxide dismutase (SOD) and catalase (CAT)) were determined in serum using ELISA kits obtained from My Biosource, San Diego, California, USA.

\section{Determination of gastric protective biomarkers}

Ulcer protective biomarkers nitric oxide (NO) and prostaglandin E2 (PGE2) were determined in gastric tissue using ELISA kits obtained from My Biosource, San Diego, California, USA.

\section{Histopathological examination}

The formaldehyde fixed stomach is paraffin-embedded, cut into sections, then stained with Hematoxylin-Eosin (H\&E). The slides were examined microscopically.

\section{Statistical analysis}

Ulcer Inhibition was expressed in percentage. Results are reported as mean \pm SD. Data were compared by one-way analysis of variance (ANOVA), followed by LSD using SPSS version 25 . P < 0.05 indicates significance difference(Armitage and Berry, 1987).

\section{Results}

\section{Active constituents of Plantago major (GC-MS)}

The GC-MS analysis of Plantago major extract was presented in Figure (1) and Table (1). The results showed that the plant contain high percent of heptacosane $(10.11 \%)$, oxiraneoctanoic acid, 3octyl-, cis $(9.34 \%)$, phytol $(8.94 \%)$, and hexadecane $(8.79 \%)$, followed by squalane $(6.99 \%)$, digitoxin $(6.92 \%)$, nonadecane $(5.82 \%)$ and hexadecane $(5.58 \%)$, and many other active constituents. 
Egypt. J. of Nutrition and Health Vol. 16 No. 1 January (2021)

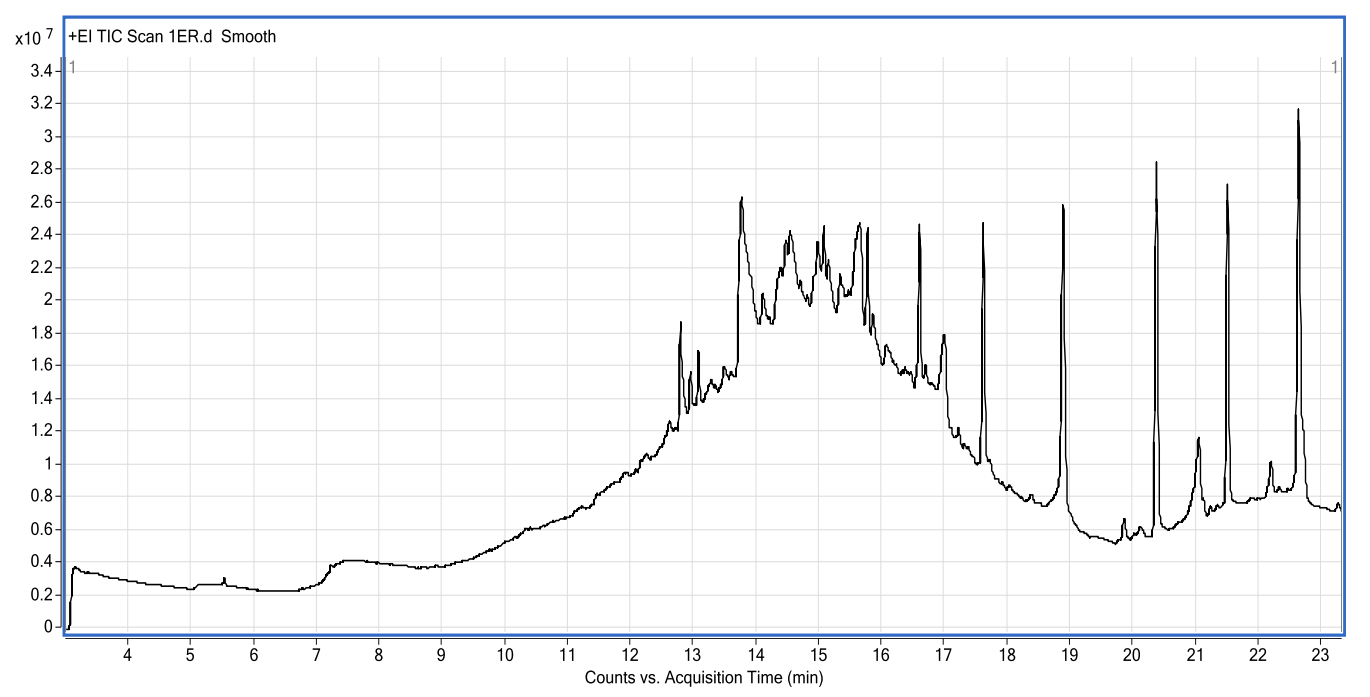

Figure (1):

Gas chromatography-mass spectroscopy (GC-MS) spectra of the Plantagomajor active constituents 
Eman M. et al

Table (1)

Active constituents of Plantago major (gas chromatography-mass spectroscopy, GC-MS)

\begin{tabular}{|c|c|c|c|}
\hline & Constituents & RT (min) & Concentrations (\%) \\
\hline 1 & Hyodeoxycholic acid & 12.204 & 2.73 \\
\hline 2 & Hexadecanoic acid, 2-bromo & 12.614 & 1.98 \\
\hline 3 & Gitoxigenin & 12.827 & 2.26 \\
\hline 4 & Rhodopin & 12.95 & 1.02 \\
\hline 5 & Oleic acid & 13.077 & 0.81 \\
\hline 6 & Batilo & 13.266 & 0.98 \\
\hline 7 & Vitexin & 13.512 & 1.2 \\
\hline 8 & Oxiraneoctanoic acid, 3-octyl-, cis & 13.778 & 9.34 \\
\hline 9 & Octadecanoic acid, 4-hydroxybutyl ester & 14.127 & 1.02 \\
\hline 10 & Phytol & 14.541 & 8.94 \\
\hline 11 & Heneicosane, 11-cyclopentyl- & 14.956 & 0.44 \\
\hline 12 & Erucic acid & 15.05 & 1.48 \\
\hline 13 & 14-Octadecenal & 15.341 & 1.88 \\
\hline 14 & Demecolcine & 15.583 & 3.65 \\
\hline 15 & Geranylisovalerate & 15.763 & 1.32 \\
\hline 16 & Heneicosane, 11-cyclopentyl & 16.071 & 2.28 \\
\hline 17 & Octadecanoic acid, 10-oxo-, methyl ester & 16.563 & 3.26 \\
\hline 18 & Cholic acid & 16.945 & 2.28 \\
\hline 19 & Neronine, $4 \beta, 5$-dihydro- & 17.207 & 0.77 \\
\hline 20 & Hexadecane & 17.605 & 5.58 \\
\hline 21 & Heptacosane & 18.868 & 10.11 \\
\hline 22 & Digitoxin & 19.807 & 6.92 \\
\hline 23 & Squalane & 20.361 & 6.99 \\
\hline 24 & Codeine & 21.021 & 4.01 \\
\hline 25 & Nonadecane & 21.493 & 5.82 \\
\hline 26 & Glaucine & 22.161 & 3.74 \\
\hline 27 & Hexadecane & 22.641 & 8.79 \\
\hline 28 & 9-Octadecenamide, (Z) & 23.256 & 0.39 \\
\hline 29 & Non-identified compounds & 3.26 & 0.01 \\
\hline
\end{tabular}

Total antioxidants, flavonoids and phenols contents of Plantago major

Plantago major contain $356.63 \pm 6.90$ (mg/ $100 \mathrm{~g}$ ascorbic acid) total antioxidants, $294.13 \pm 4.20$ (mg/ $100 \mathrm{~g}$ quercetin) total flavonoids, and $9478.1 \pm 20.10$ (mg/ $100 \mathrm{~g}$ gallic acid) total phenols (Table 2). 
Egypt. J. of Nutrition and Health Vol. 16 No. 1 January (2021)

Table (2)

Total antioxidants, flavonoids, and phenols of Plantago major

\begin{tabular}{l|c}
\hline \multicolumn{1}{c|}{ Antioxidant constituents } & Mean \pm SE \\
\hline Total antioxidants $(\mathrm{mg} / 100 \mathrm{~g}$ ascorbic acid equivalent) & $356.69 \pm 6.90$ \\
\hline Total flavonoids (mg/ 100 g quercetin equivalent) & $294.13 \pm 4.20$ \\
\hline Total phenols $(\mathrm{mg} / 100 \mathrm{~g}$ gallic acid equivalent) & $9478.1 \pm 20.10$ \\
\hline
\end{tabular}

Values were presented as the mean of 3 replicates \pm SD.

\section{Total fatty acids contents of Plantago major}

Total fatty acids(FA) of Plantago major was presented in Figure (2) and Table (3). The Plantago major contains high percent of linoleic acid $(33.79 \%)$, oleic acid $(29.41 \%)$, palmitic acid $(19.25 \%)$, followed by lauric acid (8.53\%), stearic acid (4.24\%) and linolenic acid (3.43\%), and low percent of gondoic acid $(1,35 \%)$.

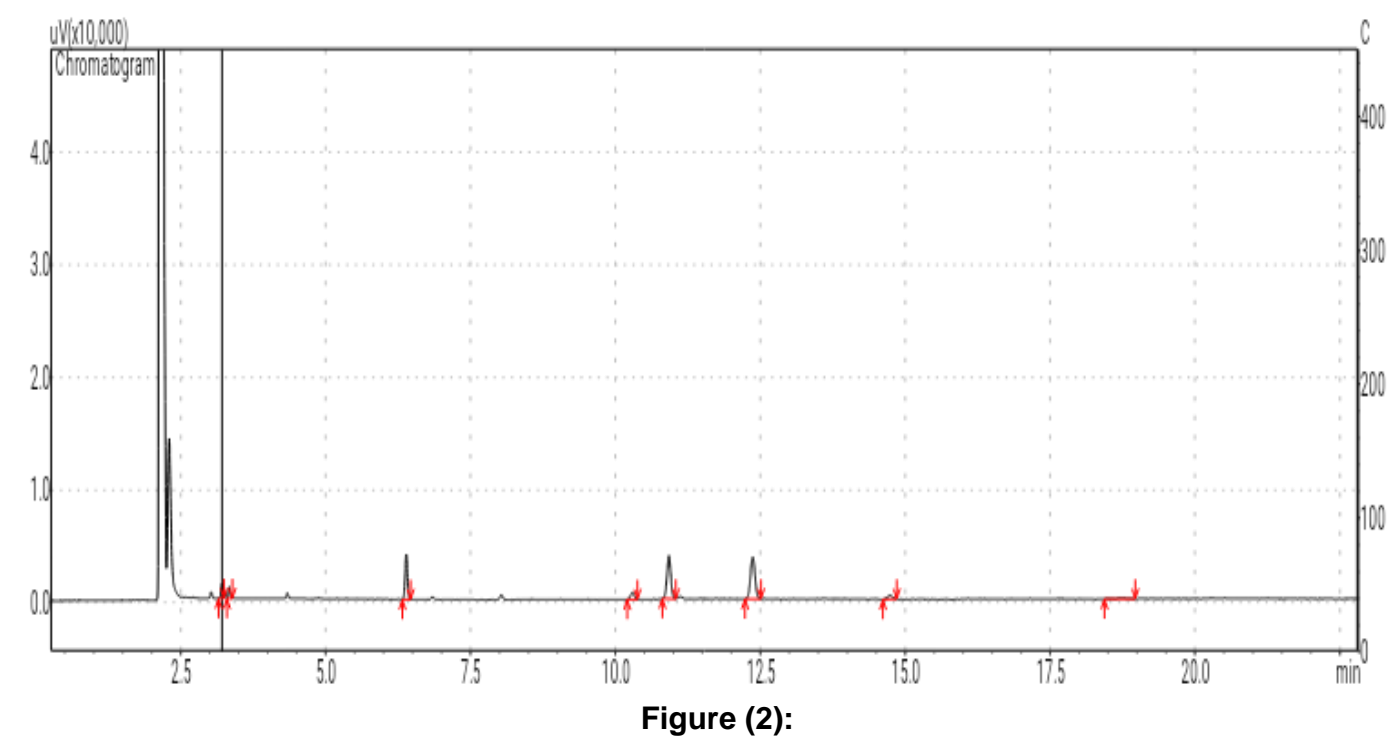

Fatty acids content of Plantago major(gas chromatography, GC)

Table (3)

Fatty acids content of Plantago major

\begin{tabular}{l|c|c}
\hline \multicolumn{1}{c|}{ Fatty acids } & Name & Relative distribution \% \\
\hline $\mathrm{C} 12: 0$ & Lauric acid & 8.53 \\
\hline $\mathrm{C} 16: 0$ & Palmitic acid & 19.25 \\
\hline $\mathrm{C} 18: 0$ & Stearic acid & 4.24 \\
\hline $\mathrm{C} 18: 1 \omega 9$ & Oleic acid & 29.41 \\
\hline $\mathrm{C} 18: 2 \omega 6$ & Linoleic acid & 33.79 \\
\hline $\mathrm{C} 18: 3 \omega 3$ & Linolenic acid & 3.43 \\
\hline $\mathrm{C} 20: 1 \omega 9$ & Gondoic acid & 1.35 \\
\hline
\end{tabular}

\section{Gastric gross structure}

In the IND group, the stomach showing diffuse and multiple ulcer formation with depressed centre and elevated borders. While stomach of the Plantago WE+IND pretreated group showing starting of ulcer healing signs. In the Plantago EE+IND pretreated group stomach showing advanced 


\section{Eman M. et al}

ulcer healing signs. While in the Panto+IND pretreated group the stomach showing complete ulcer healing with apparently healthy intact mucosawas seen (Figure3).

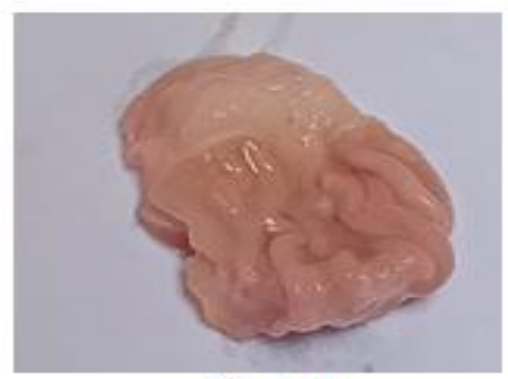

Control

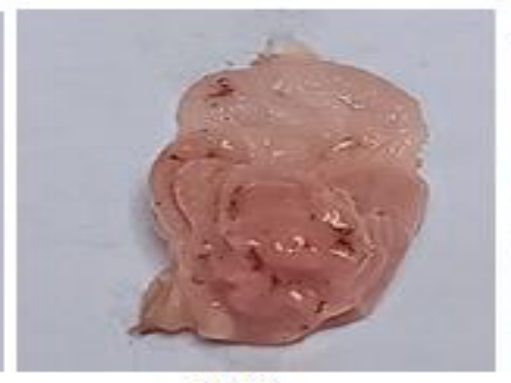

IND

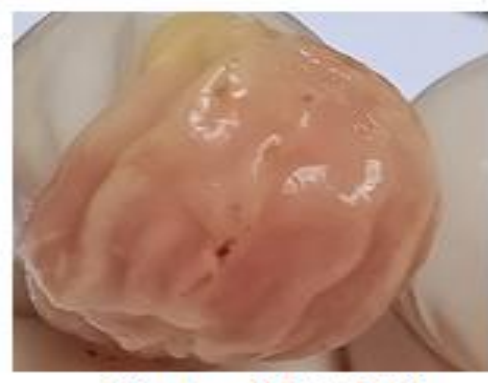

Plantago VE + IND
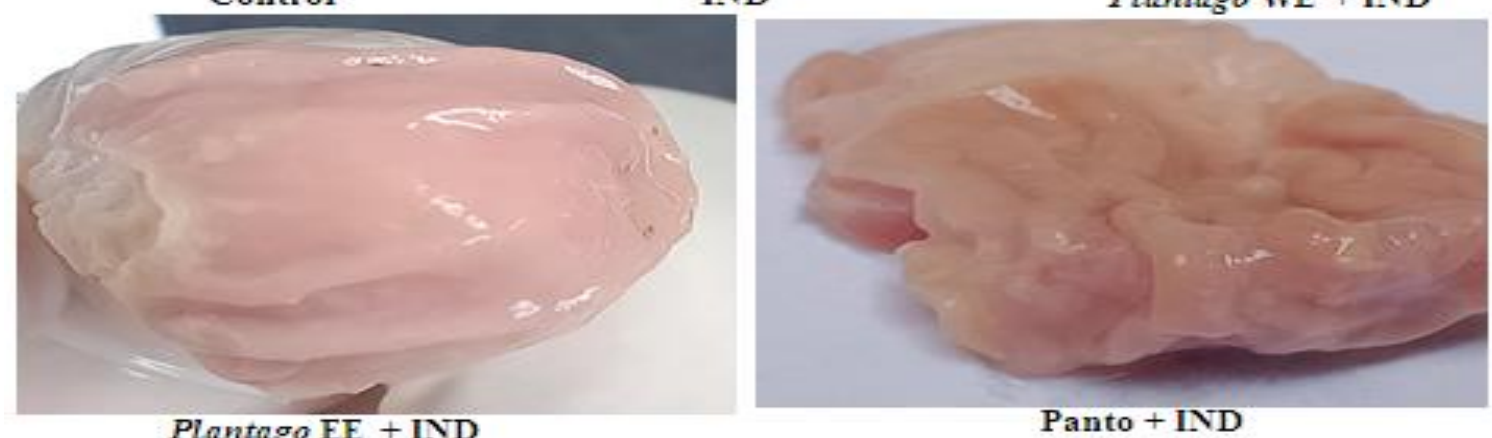

Figure(3):

Effect of Plantago major extracts and Pantoon gastric gross structure in rats.

Stomach of the -ve control group showing intact mucosa. In IND group the stomach showing diffuse multiple ulcer formation with depressed centre and elevated borders. While stomach of Plantago WE+IND pretreated group showing starting of ulcer healing signs. Stomach of Plantago EE+IND pretreated group showing advanced ulcer healing signs. In Panto +IND pretreated group the stomach showing complete ulcer healing with apparently healthy intact mucosa.

\section{Effect of Plantago major extracts on gastric mucosal lesions biomarkers}

In IND group, there was a significant increase in UI compared with control group $(p<0.001)$. On the other hand, in both Plantago WE or EE + IND and Panto + IND groups there was a significant decrease $(p<0.001)$ in UI compared with IND group. A significant difference was found between Plantago WE and the other two pretreated groups in IU with $51.73 \%$ inhibition of ulceration. Besides, there was a significant difference between the Panto+IND group and the Plantago EE+ IND group. The percentage inhibition of ulceration accounted $55.63 \%$ and $76.49 \%$ for the Plantago EE+ IND and the Panto+IND groups, respectively (Table 4).

Gastric $\mathrm{pH}$ decreased significantly $(\mathrm{p}<0.001)$, while total gastric acidity significantly increased $(p<0.001)$ in the IND group compared with the control group. Meanwhile, gastric $\mathrm{pH}$ increased significantly concurrent with a significant decrease in total gastric acidity in Plantago WE + IND, Plantago EE +IND, and Panto + IND groups compared with the IND group $(p<0.001)$.In total gastric acidity, a significant difference was found between water Plantago extract and the other two pretreated groups. Besides, there was a significant difference between the Panto+IND group and the Plantago EE+ IND group (Table 4). 
Egypt. J. of Nutrition and Health Vol. 16 No. 1 January (2021)

Table(4)

Effect of Plantago major extracts and Panto on ulcer index (UI), percentage inhibition of ulceration, gastric $\mathrm{pH}$, and total gastric acidity in IND-induced ulceration in rats.

\begin{tabular}{l|c|c|c|c}
\hline Experimental groups & UI $\left(\mathrm{mm}^{2}\right)$ & $\begin{array}{c}\text { Inhibition of } \\
\text { Ulceration (\%) }\end{array}$ & Gastric $\mathrm{pH}$ & T. gastric acidity \\
\hline Control & - & - & $5.05 \pm 0.24$ & $56.35 \pm 2.51$ \\
\hline IND & $10.21 \pm 0.87^{\mathrm{a}}$ & - & $2.23 \pm 0.23^{\mathrm{a}}$ & $111.50 \pm 6.11^{\mathrm{a}}$ \\
\hline Plantago WE + IND & $5.03 \pm 0.33^{\mathrm{b}}$ & 51.73 & $4.12 \pm 0.39^{\mathrm{b}}$ & $81.05 \pm 4.41^{\mathrm{b}}$ \\
\hline Plantago EE + IND & $4.53 \pm 0.41^{\mathrm{b}, \mathrm{c}}$ & 55.63 & $4.06 \pm 0.24^{\mathrm{b}}$ & $73.47 \pm 3.86^{\mathrm{b}, \mathrm{c}}$ \\
\hline Panto + IND & $2.40 \pm 0.35^{\mathrm{b}, \mathrm{c}, \mathrm{d}}$ & 76.49 & $3.91 \pm 0.22^{\mathrm{b}}$ & $64.41 \pm 3.62^{\mathrm{b}, \mathrm{c}, \mathrm{d}}$ \\
\hline
\end{tabular}

Data are represented as mean \pm SD $(n=10)$.

a Significant versus control, ${ }^{b}$ significant versus IND, ${ }^{c}$ significant versus Plantago WE + IND, and ${ }^{d}$ significant versus Plantago EE + IND ( $p \leq 0.05)$.

\section{Effect of Plantago major extracts on serum oxidative stress biomarkers}

In IND group, there was a significant increase in the serum MDA level with significant decrease in the serum SOD and CAT levels compared with control group $(p<0.001)$. On the other hand, in Plantago WE+ IND, Plantago EE + IND and Panto + IND pretreated groups there was a significant decrease $(p<0.001)$ in MDA concurrent with significant increases in the SOD and CAT levels compared with the IND group. A significant difference was found between Plantago WE+ IND group and the Plantago EE + IND in all tested oxidative stress biomarkers. Besides, there was significant differences between the Panto+IND group and the Plantago extracts pretested group in the serum levels of MDA and SOD (Figure 4).

\section{Effect of Plantago major extracts on gastric protective biomarkers}

In IND group, there were significant decreases in the gastric NO and PGE2 levels compared with the control group $(\mathrm{p}<0.001)$. On the other hand, in both Plantago WE or EE + IND and Panto + IND groups there were significant increases $(p<0.001)$ in gastric NO and PGE2 level scompared with the IND group. A significant difference was found between water Plantago extract+ IND group and both the Plantago EE+IND and Panto+IND groups in gastric NO content (Table 5). 
Eman M. et al
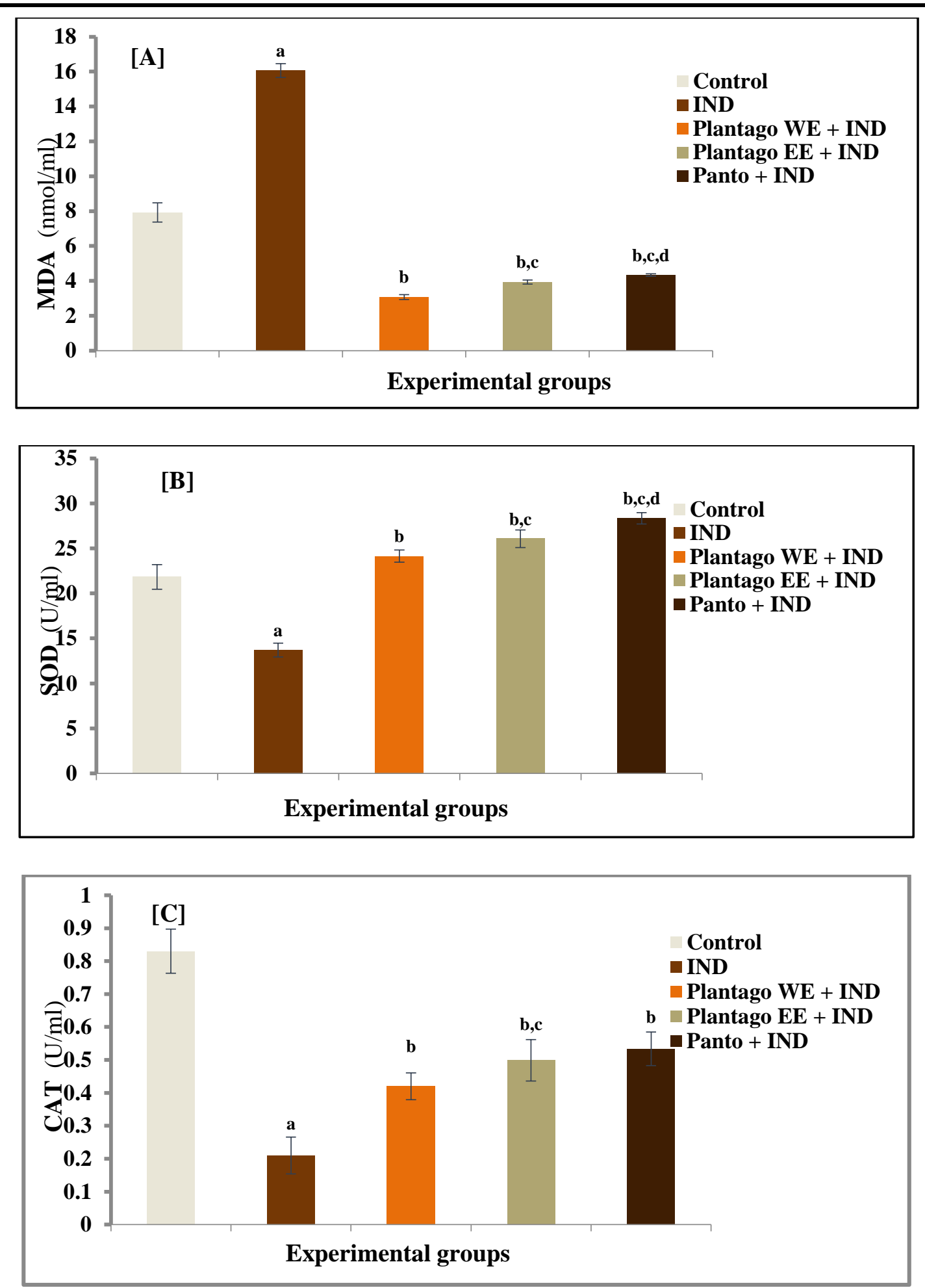

Figure(4):

Effect of Plantago major extracts and Panto on serum antioxidant malondialdehyde (MDA) [A], superoxide dismutase (SOD) [B], and catalase (CAT) [C] levels in IND-induced ulceration in rats. Data are represented as mean \pm SD $(n=10)$.

a Significant versus control, ${ }^{b}$ significant versus IND, ${ }^{c}$ significant versus Plantago WE + IND, and ${ }^{d}$ significant versus Plantago EE + IND ( $p \leq 0.05)$. 
Egypt. J. of Nutrition and Health Vol. 16 No. 1 January (2021)

Table (5)

Effect of Plantago major extracts and Panto ongastric nitric oxide (NO) and prostaglandin E2 (PGE2) concentrations in IND-induced ulceration in rats

\begin{tabular}{c|c|c}
\hline Experimental groups & NO $(\mu \mathrm{mol} / \mathrm{g})$ & PGE2(ng/g) \\
\hline Control & $7.02 \pm 0.35$ & $120.62 \pm 4.77$ \\
\hline IND & $2.29 \pm 0.37^{\mathrm{a}}$ & $85.87 \pm 4.36^{\mathrm{a}}$ \\
\hline Plantago WE + IND & $4.91 \pm 0.36^{\mathrm{b}}$ & $115.36 \pm 5.35^{\mathrm{b}}$ \\
\hline Plantago EE + IND & $5.81 \pm 0.53^{\mathrm{b}, \mathrm{c}}$ & $117.63 \pm 4.11^{\mathrm{b}}$ \\
\hline Panto+ IND & $6.25 \pm 0.74^{\mathrm{b}, \mathrm{c}}$ & $119.06 \pm 3.43^{\mathrm{b}}$ \\
\hline
\end{tabular}

Data are represented as mean \pm SD $(n=10)$.

${ }^{a}$ Significant versus control, ${ }^{b}$ significant versus IND, ${ }^{c}$ significant versus Plantago WE + IND, and ${ }^{d}$ significant versus Plantago EE + IND ( $p \leq 0.05)$.

\section{Effect of Plantago major extracts on the gastric tissue histopathological changes}

The stomach of the (-ve) control group shows normal stomach layers; normal lamina epithelialis, lamina propria, submucosa, and muscularis mucosa (Figure5.A).In IND group, the stomach showing ulcerative gastritis, complete destruction of all stomach layers with mononuclear cells infiltration and congested blood vessels (Figure5.B). While The stomach from the Plantago WE + IND group showing early stages of ulcer healing; the immature granulation tissue formation, mononuclear cells infiltration, and dilated blood vessels (Figure5.C). Stomach from the Plantago EE + IND group showing advanced stages of ulcer healing; the mature granulation tissue formation and the mononuclear cells infiltration (Figure5.D).Stomach from the Panto+ IND group showing complete ulcer healing; the intact stomach layers; mucosa, submucosa, and musculosa (Figure5.E).

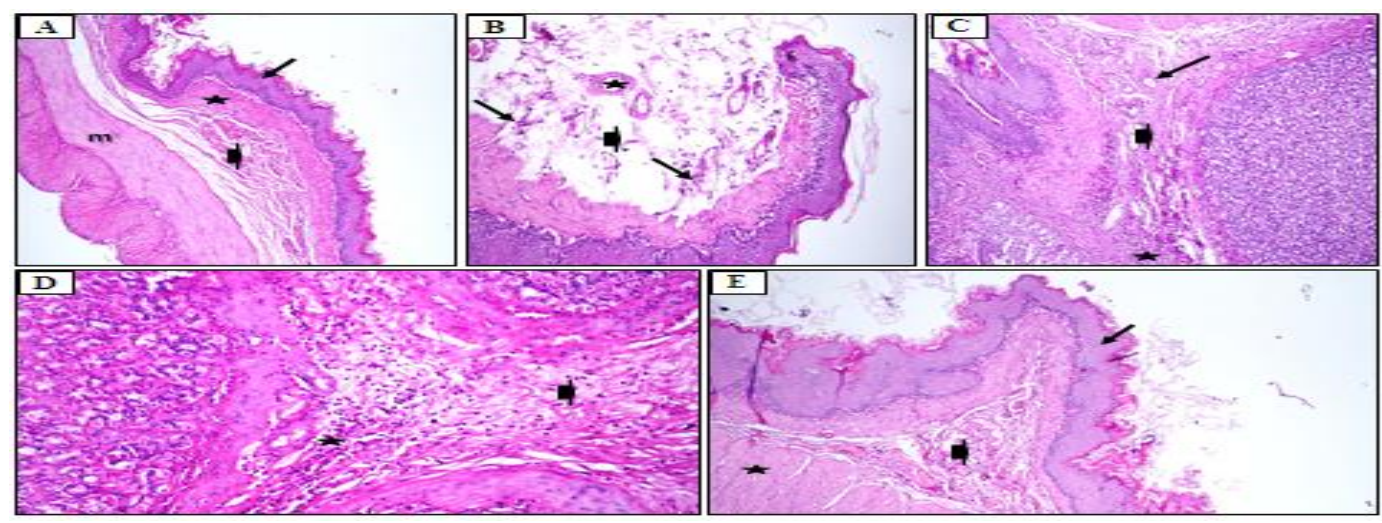

Figure (5):

Effect of Plantago major extracts and Pantoon histopathological alteration on gastric tissue in IND-induced ulceration in rats (H\&E X 200).

The stomach from control group showing normal stomach layers; note the normal lamina epithelialis (arrow), lamina propria $\left({ }^{*}\right)$, submucosa (arrow head), and muscularis mucosa (m) (Fig. A). In IND group showing ulcerative gastritis; note the complete destruction of all stomach layers (arrow head) with mononuclear cells infiltration(arrows) and congested blood vessels $\left({ }^{*}\right)$ (Fig. B). Stomach from the Plantago WE + IND group shows early stages of ulcer healing; note the granulation tissue formation (arrow head), mononuclear cells infiltration $\left({ }^{*}\right)$, and dilated blood vessels (arrow) (Fig. C). 


\section{Eman M. et al}

Stomach from the Plantago EE + IND group shows advanced stages of ulcer healing; note the mature granulation tissue formation (arrow head) and the mononuclear cells infiltration (*) (Fig. D).Stomach from the Panto + IND group shows complete ulcer healing; note the intact stomach layers; mucosa (arrow), submucosa (arrow head), and musculosa (*) (Fig. E).

\section{Discussion}

Gastric ulcer is the most prevalent gastrointestinal disorders and the complications worldwide (Chow and Sung, 2009).Although conventional treatments are effective, both clinical and experimental studies have demonstrated that traditional herbal medicines exhibit therapeutic benefit for gastric ulcer (Biet al., 2014). The phyto constituents found in Plantago major as flavonoids, tannins, steroids, triterpenoids, phenolic acids, and alkaloids have antioxidant properties (Nayaket al., 2011 and Nyi and Dytha, 2019). These components are known to protect the gastric mucous membranes (Kobeasyet al., 2013).The present study evaluated the gastroprotective effects of Plantago major water and ethanol extracts against IND-induced ulcers in rats. Besides, comparing its effects with Panto as reference drug.

In the present study the total antioxidants, total flavonoids and total phenols content of Plantago major were major to that obtained by Kobeasyet al., (2011) that the ethanolic extract of Plantago major leaves, had the highest total phenols, flavonoid and tannin contents which explains the highest antioxidant activity of ethanol extract of Plantago major leaves. Jyotiet al., (2017) reported that Plantago major extracts have antioxidant compounds, which is used to prevent diseases related to oxidative processes. While,different results were found by Karimaet al., (2015) who reported that the total phenols and total flavonoids content of different extracts from Plantago major leaves were (petroleum ether, ethyl acetate and aqueous fractions) were low .

Plantago major contained high percent of linoleic acid, oleic acid, palmitic acid .These finding agreed with those obtained by Liu et al., (2002) who reported that the major fatty acids of Plantago major leaves were linoleic and palmitic acid. Kobeasyet al.,(2011) reported that Plantago leaves has a high percentage of linolenic acid. Manjari and Das, (2000) and Manjari and Das, (2000) reported that increased dietary intake of polyunsaturated fatty acids (PUFAs) is known to be associated with a decrease in the incidence of peptic ulcer disease possibly due to increase in the synthesis of prostaglandins. Diets or supplements high in linolenic acid (C18:3) and linoleic acid (C18:2), polyunsaturated fatty acids (PUFAs) are required for PGE2 synthesis(Kirkupet al., 2010), the PGE2 exerts a potent protective activity in vitro which is independent on neural, vascular and hormonal factors (Brzozowskiet al., 2005).

In the present study, there was a significant increase in UI in the IND group compared with the control group. On the other hand, in both Plantago WE or EE+IND and Panto + IND groups there was significant decrease in UI compared with IND group. A significant difference was found between water Plantago extract and the other two pretreated groups with $51.73 \%$ inhibition of ulceration. Besides, there was a significant difference between the Panto+IND group and the Plantago EE+ IND group. Our results agree with Atta and El-Sooud, 2004; Kim et al., 2011 and Moramet al., (2016). Increasing in ulcer index in the ulcerated rats might be ascribed to either inhibition of prostaglandin synthesis or formation of free radicals (Atta et al., 2005 and Chadanet al., 2013).The gastroprotective effect of Plantago major could be attributed to its content of variable amounts of triterpens, flavonoids, tannins, and polyunsaturated fatty acid like linoleic acid (Atta and Mouneir, 2004 and Rakeshet al., 2011). 


\section{Egypt. J. of Nutrition and Health Vol. 16 No. 1 January (2021)}

Triterpens are the active constituents that have been claimed to be effective as an anti-ulcer agent because it protects the mucosa against acid effects (De Pasquale et al., 1995).In addition, tannins is an astringent which forms a protective layer of Pellicle over the lining in the site of ulcer thereby to prevent the absorption of toxic substances and to resist the attack of the proteolytic enzymes (Nwaforet al., 1996).

The $\mathrm{pH}$ gives an indicator of gastric secretions acidity. Low $\mathrm{pH}$ value is a sign of low concentration of hydrogen ions in gastric juice. This was associated with ulcer disease and gastric harm in animal models (Lullmannet al., 2000).In the present study, gastric pH increased significantly concurrent with significant decrease in total gastric acidity in both Plantago WE or EE extracts + IND, and Panto + IND groups compared with the IND group. In total gastric acidity, a significant difference was found between water Plantago extract and the other two pretreated groups. Besides, there was a significant difference between the Panto +IND group and the Plantago EE+ IND group. several studies showed that indomethacin caused alterations in gastric secretions of rats. Low $\mathrm{pH}$ value has been linked to causing ulcers and destroying the stomach in animals(Yesildaet al., 1993; Beck et al., 2000; Biplabet al., 2011 and Muhammed et al., 2012). This lesion occurs through internal defeats such as pepsin and oxidative stress and external factors such as drugs and chemicals that damage the gastric mucosal epithelium (Lullmannet al. 2000 and Gazwi and Mahmoud, 2018).

Indomethacin stimulates the metabolites of reactive oxygen in animal experiments, which may participate to mucosal damage and devastate cellular antioxidant enzymes that act as the first cellular defense line against oxidative damage (El-Missiryet al., 2001 and Chattopadhyay et al., 2006). In this study there was a significant increase in the serum MDA level with significant decreases in the serum SOD and CAT levels in the IND group compared with the control group. On the other hand, in both Plantago WE or EE + IND and Panto + IND pretreated groups there was a significant decrease in MDA concurrent with significant increases in the SOD and CAT levels compared with IND group. These results agree with (Kim et al., 2011; Allam and EL-Gohary, 2017 and Nwaonukuruet al., 2018). Plantago WE or EE + IND showed a noticeable suppression of oxidative damage because of its radical scavenging activity, it conveyed MDA level nearer to ordinary levels. This could be explained by the activated components in Plantago extract that contain flavonoids and terpenoids which play vital role as a scavenger of free radicals and perform powerful antioxidant function (Ali et al ., 2013).

In IND group, there was significant decrease in the gastric NO and PGE2 levels compared with the control group. On the other hand, in both Plantago WE or EE + IND and Panto + IND groups there were significant increase in gastric NO and PGE2 levels compared with IND group. This result agree with Lanaset al., (2000) and Cadirciet al., (2007). The decrease in NO biosynthesis may be due to diminished activity of NO synthase (NOS) (Tripp and Tepperman,1995). The indomethacin causes reduction of the activity of endothelial nitric oxide synthase (eNOS) and thus reduce the level of NO (Slomianyet al., 1999). All pretreated groups showed significant increase in NO levels compared to the IND group. The potential mechanism for increasing the NO level in Plantago WE or EE pretreated groups could be attributed to its flavonoids content which have potent antioxidant and gastro protective properties (Matsuda et al.,2003).

Histological examination of the stomachs demonstrated that the stomach from the IND group showing ulcerative gastritis, complete destruction of all stomach layers with mononuclear cells infiltration and congested blood vessels. These results agree with several studies where the indomethacin caused marked damage to the gastric mucosa such as focal coagulative necrosis, leukocytic infiltration, and blood vessels congestion (EL-Moselhyet al., 2009; El-Demerdash et al., 


\section{Eman M. et al}

2010 and Shahin et al., 2018). These results could be attributed to a significant increase in lipid peroxidation and generation of oxygen free radicals (Kim et al., 2011). While the recovery of gastric mucosa of Plantago WE, EE + IND and Panto+ IND presumably relies upon vaso ligating action. These action increments mucosal blood flow and promote angiogenesis, a key factor in ulcer recuperating (Kontureket al., 1993).

In conclusion, our results showed that water and ethanol extracts of Plantago major showed gastroprotective effects against IND-induced gastric ulcer. These impacts may be due to the presence of flavonoids, tannins, steroids, triterpenoids, phenolic acids, alkaloids and polyunsaturated fatty acids in Plantago extracts which induce inhibition in lipid peroxidation and enhancement in enzymatic antioxidant defenses.

\section{References}

Abud, M.A., Molina,A., Wendel, G.H., Juan Hikawczuk, V.E., Lilian, E. Pelzer, L.E., María, A.O. and Saad, J.R. 2012.

Gastroprotective effects of Plantago major and metabolites in rats. Lat. Am. J. Pharm., 31 (8): 1203-1206.

Ali N., Peyman M., Milad M., Shahin A. andSoheil, J. 2013.

Therapeutic uses and pharmacological properties of Plantago major L. and its active constituents. J. Basic. Appl. Sci. Res., 3(9).

Allam, M.M. and EL-Gohary, O.A. 2017.

Gastroprotective effect of ghrelin against indomethacin- induced gastric injury in rats: possible role of heme oxygenase-1 pathway. Gen. Physiol. Biophys, 36: 321-330.

AOAC (Association of Official Agricultural Chemists).

Official Methods of Analysis, 21 ${ }^{\text {th }}$ Edition 2019:19- 20.

Armitage, G.Y. and W.G. Berry (1987):

Statistical methods 7th Ed Ames., lowa State University. Press .39-63.

Arvouet-Grand, A., Vennat, B., Pourrat, A. and Legret, P. 1994.

Standardisation d'un extrait de propolis et identification des principaux constituants. J. Pharm Belg., 49(6):462-468.

Atta, A.H. and Abo El-Sooud, K. 2004.

The ant nociceptive effect of some Egyptian medicinal plant extracts. J. Ethnopharmacol., 95(2-3): 235-8.

Atta, A.H. and Mouneir, S.M. 2004.

Antidiarrheal activity of some Egyptian medicinal plant extracts, J. Ethnopharmacol , 92: 303 309.

Atta, A.H., Soad M. N. and Samar, M.M. 2005.

Anti ulcerogenic effect of some plants extracts. Natural Product Radiance., 4(4): 258-263. 


\section{Egypt. J. of Nutrition and Health Vol. 16 No. 1 January (2021)}

Beck, P.L., Xavier, R., Lu, N., Nanda, N.N., Dinauer, M., Podolsky, D.K. and Seed, B. 2000. Mechanisms of NSAID-induced gastrointestinal injury defined using mutant mice. Gastroenterology, 119 (3): 699 -705.

Bhattacharya, S., Chaudhuri, S.R., Chattopadhyay, S. and Bandyopadhyay, S.K. 2007. Healing properties of some Indian medicinal plants against indomethacin-induced gastric ulceration of rats.J. Clin. Biochem.Nutr., 41:106-114.

Bi, W.P., Man,H.B. and Man, M. Q. 2014.

Efficacy and safety of herbal medicines in treating gastric ulcer: a review. World J. Gastroenterol., 20(45):17020 -17028.

Biplab, A.; Sudhir, K.Y.; Kshama, R.; Sandip, K.B. and Subrata, C. 2011.

Black tea and the aflavins assist healing of indomethacin-induced gastric ulceration in mice by antioxidative action, EvidBasedComplem Alt Med., 11: 11 - 22.

Brzozowski T., Konturek P.C., Konturek S.J., Brzozowska, and Pawlik, I.T. 2005.

Comparison of prostaglandin and cimetidine in protection of isolated gastric glands against indomethacin injury.J. Physiol. and Pharmacol., 56 Suppl 5:75-88

Cadirci, E., Suleyman, H.,Aksoy, H.,Halici, Z., Ozgen, U., Koc, A. and Ozturk, N. 2007. Effects of Onosmaarmeniacum root extract on ethanol induced oxidative stress in stomach tissue of rats.Chem. Biol. Interact., 170(1):40-48.

Chandan, N.G., Deb, T., and Bhargavi, S.M. 2013.

Evaluation of anti-ulcer activity of Tinosporacordifolia in albino rats.Int. J. Pharm. Bio.Sci., 4(2): $\quad 78-85$.

Chattopadhyay, I., Bandyopadhyay, U., Biswas, K., Maity, P. and Banerjee, R.K. 2006.

Indomethacin inactivates gastric peroxidase to induce reactive oxygen- mediated gastric mucosal injury and curcumin protects it by preventing peroxidase inactivation and scavenging reactive oxygen. FreeRadic. Biol. Med., 40(8):1397-1408.

Cheng, Y.T., Lu, C.C. and Yen, G.C. 2017.

Phytochemicals enhance antioxidant enzyme expression to protect against NSAID-induced oxidative damage of the gastrointestinal mucosa. Mol Nutr Food Res, 61(6): doi: 10.1002/mnfr.201600659.

Chow D.K. and Sung, J. J. 2009.

Non-NSAID non-H.pylori ulcer disease. Best Practice \& Res. Clin. Gastroenterol., 23(1):3-9.

Dashputre, N.L. and Naikwade, N.S. 2011.

Evaluation of antiulcer activity of methanolic extract of Abutilon indicum Linn leaves in experimental rats. Int. J. Pharm. Sci. Drug Res., 3:97-100.

De Pasquale, Germanmo R., Keita M.P., Sanogo A.R. and lauk, L. 1995.

Antiulcer activity of Pteleopsissuberosa, J. Ethnopharmacol, 47(1): 55-58. 


\section{Eman M. et al}

El-Demerdash, E., Hala, O.E., Noha, M.A and Mohamed, Z.G. 2010.

The potential therapeutic effect of nitric oxide modulators in experimentally-induced gastriculcers.Drug Discoveries \& Therapeut., 4(4): 276-284.

El-Missiry, M.A., El-Sayed, I.H. and Othman, A.I. 2001.

Protection by metal complexes with SOD mimetic activity against oxidative gastric injury induced by indomethacin and ethanol in rats. Ann Clin Biochem., 38:694-700.

EL-Moselhy, M.A., Abdel-Hamid, N.M, and Abdel- Raheim, S.R. 2009.

Gastroprotective effect of nicorandil in indomethacin and alcohol-induced acute ulcers.Appl. Biochem. Biotechnol.,152 (3): 449-459.

Gazwi,H.S.S. and Mahmoud, M.E. 2018.

Gastroprotective effect of Boragoextracts against indomethacin-induced gastric ulcer in rats. J. Food and Dairy Sci., $3^{\text {rd }}$ Mansoura International Food Congress (MIFC) October: 177 185.

Ibrahim, F.M., Attia, H.N., AlyMaklad, Y.A., Ahmed, K.A. and Ramadan,M.F. 2017.

Biochemical characterization, anti-inflammatory properties and ulcerogenic traits of some cold-pressed oils in experimental animals. PharmBiol, 55: 740-748.

Jyoti, V.M., Ashok, K.G. and Alok,M. 2017.

Quantitative study of total phenolic content and in-vitroantioxidant activity of aerial part extracts of Plantago major L. J. Pharm. Sci. \& Res., 9(11), 2033-2041.

Karima, S., S. Farida, and Mihoub,Z. M. 2015.

Antioxidant and antimicrobial activity of Plantago major. Inter. J. Pharm. \&Pharmaceut. Sci., 7(5): 58-64.

Kim, J.H., Kim, B.W., Kwon, H.J. and Nam,S.W. 2011.

Curative effect of selenium against Indomethacin -induced gastric ulcers in rats. $J$ Microbio.IBiotechnol., 21: 400 - 404.

Kirkup, S E, Cheng, Z., Elmes, M., Wathes, D.C. and Abayasekara,D.R.E. 2010.

Polyunsaturated fatty acids modulate prostaglandin synthesis by ovine amnion cells in vitro. Reproduct., 140943 - 951.

Kobeasy, M., Abdel-Fatah O.M., Abd El-Salam, S.M. and Mohamed, Z.M. 2013.

Gastroprotective effect of Plantago major I. against gastric injury induced by aspirin in rats.J Chemica Acta, 2 (2).

Kobeasy, M.I., Osama, M. Abdel-Fatah, Samiha M. Abd El-Salam and Zahrat El-Ola, M. 2011.

Biochemical studies on Plantago major L. and CyamopsistetragonolobaL. Inter. J. Biodiversit. \&Conservat., 3(3): 83-91.

Konturek, S.J., Brzozowski,T., Majka, J., Pytko-Polonczyk, J. and Stachura, J. 1993.

Inhibition of nitric oxide synthase delays healing of chronic gastric ulcers. Eur J Pharmacol., 239: 215-217. 


\section{Egypt. J. of Nutrition and Health Vol. 16 No. 1 January (2021)}

Lanas, A., Bajador, E., Serrano, P., Fuentes, J., Carreňo, S., Guardia, J., Sanz, M.;Montoro, M. and Sainz, R. 2000.

Nitro vasodilators, low-dose aspirin, other non-steroidal anti-inflammatory drugs, and the risk of upper gastrointestinal bleeding. N. Eng. J. Med., 343 (12): 834 - 839.

Lee, H.L., Chua, S.S. and Mahadeva, S. 2016.

Utilization of gastroprotective strategies for no steroidal anti-inflammatory drug-induced gastrointestinal events in a major teaching hospital. HerClin Risk Manag, 12: 1649-1657.

Liu L, Ho P, Zhou Y, Hocart C. and Zhang,R. 2002.

Fatty acid profiles of leaves of nine edible wild plants: An Australian study. J. Food Lipids, 9: $65-69$.

Lullmann, H., Mohr, K., Ziegler, A. and Bieger, D. 2000.

Color atlas of pharmacology, 2nd ed., Thieme Stuttgart, New York, 166.

Manjari, V.and Das, U.N. 2000.

Effect of polyunsaturated fatty acids on dexamethasone-induced gastric mucosal damage.Prostaglandins Leukot Essent Fatty Acids, 62(2):85-96.

Matsuda, H., Morikawa, T., Ando, S., Toguchida, I. and Yoshikawa,M. 2003.

Structural requirements of flavonoids for nitric oxide production inhibitory activity and mechanism of action.Bioorg.Med.Chem.,11(9):1995-2000.

Matsui, H., Shimokawa, O., Kaneko, T., Nagano, Y. and Rai,K. 2011.

The pathophysiology of non-steroidal anti-inflammatory drug (NSAID) - induced mucosal injuries in stomach and small intestine. J Clin Biochem Nutr., 48: 107-111.

Melese, E., Asres,K., Asad,M. andEngidawork,E. 2011.

Evaluation of the antipeptic ulcer activity of the leaf extract of Plantago lanceolata $L$. in rodents. Phytother. Res., 25: 1174-1180.

Mohamed, I.K., Osama,M.A., Samiha,M.A.E. and Zahrat,M.E. 2011.

Biochemical studies on Plantago major L. and Cyamopsistetragonoloba L. Int. J. Biodivers Conserv., 3:83-91.

Moram G.S.E.; Abouzeid, N.R.A. and M. Salman 2016.

Evaluation of antiulcer activity of red pepper and garlic bulb against indomethacin induced gastric ulcer in rats: biochemical and histopathological study. EJPMR, 3(2):100-112.

Muhammed, A.V.K., Thamotharan, G., Sengottuvelu, S., Haja-Sherief, S. and Sivakumar, T. 2012. Evaluation of antiulcer activity of Ficuspumila L. leaf extract in albino rats. Glob $\mathrm{J}$ Res Med Plants Indig Med.,1(8) :340-351.

Nayak, B.,Berrios, J.D.J., Powers, J.R. and Tang,J. 2011.

Effect of extrusion on the antioxidant capacity and color attributes of expanded extradites prepared from purple potato and yellow pea flour mixes. J. Food Sci., 76:C874 -C883. 


\section{Eman M. et al}

Nazarizadeh, A., Mikaili, P., Moloudizargari, M., Aghajanshakeri, S.H..and Javaherypour,S. 2013.

Therapeutic uses and pharmacological properties of Plantago major L. and its active constituents. J. Basic. Appl. Sci. Res.,3(9): 212-221.

Nwafor, P.A., Effraim, K.D. and Jacks,T.W. 1996.

Gastroprotectective effects of aqueous extract of Khayasenegalensisbark in indomethacin induced ulceration in rats. W. Afr. J. Pharmacol.Drug Res., 12: 46-50.

Nwaonukuru, E.,Olaniyi, O.O.1. and Oluwole,F.S. 2018.

Possible gastroprotective mechanisms of Dacryodesedulis extract in indomethacin- induced gastric ulceration in male Wistar rats. J. PharmaceutRes.Inter., 22(1): 1-12.

Nyi M. S. and A.D.Dytha ,2019.

Antipyretic activity of plantain (Plantago major L.) leaves extract in yeast - induced mice. Drug Invention Today, 12(7):1588-1590.

Ozaslan, M., Karagoz, I., Kiliç, I., Cengiz, B., Kalender, E., Güldür, E., Karagoz, A. and Zümrütdal, E. 2009.

Effect of Plantagomajor sap on Ehrlich Ascites tumours in mice.African J. Biotech., 8 (6): 955959.

Ozaslan, M., Karagöz, K., Kalender, M.E., Kilic, I.H., Sari, I. and Karagöz,A. 2007.

In vivo antitumoral effect of PlantagomajorL. extract on Balb/C mouse with ehrlich ascites tumor. Am.J. Chin. Med., 35:841-851.

Prieto, P., Pineda, M. and Aguilar,J.R.1999.

Spectrophotometric quantitation of antioxidant capacity through the formation of a phosphomolybdenum complex: Specific application to the determination of vitamin E. Anal Biochem., 269(2):337-41.

Rakesh, M.R., Kabra, M.P., and Rajkumar,V.S. 2011.

Evaluation of antiulcer activity of castor oil in rats. Inter. J. Res. in Ayurveda and Pharm., 2(4):1349-1353 .

Saheed, S., Taofeeq, G.,Taofik, S.,Emmanuel, A., Abdulhakeem, S.,Ismaila, N. and Abdulazeez,B. 2015.

Indomethacin-induced gastric ulceration in rats: Protective roles of Spondiasmombin and Ficus exasperate. Toxicology Reports, 2: 261-267.

Samuelsen, A.B. 2000.

The traditional uses, chemical constituents and biological activities of Plantago major L.A review. J. Ethnopharm, 71:1-21.

Santana, P.M., Miranda, M., Payrol, J.A., Silva, M., Hernández, V. and Peralta,E. 2013.

Gas chromatography-mass spectrometry study from the leaves fractions obtained of Vernonanthura patens (Kunth) H. Rob Int J Org Chem., 03(02):105-9. 


\section{Egypt. J. of Nutrition and Health Vol. 16 No. 1 January (2021)}

Shahin, N.N., Abdelkader, N.F. and Safar, M.M. 2018.

A Novel role of Irbesartan in gastroprotection against indomethacin-induced gastric injury in rats.Sci Rep., 9; 8(1):4280.

Simon, L.S. 1993.

Nonsteroidal anti-inflammatory drug toxicity.CurrOpinRheumatol, 5: 265-275.

Singleton, V.L., Orthofer, R. and Lamuela-Raventós,R.M. 1999. Analysis of total phenols and other oxidation substrates and antioxidants by means of folin-ciocalteu reagent. Methods Enzymol., 299:152-78.

Slomiany, B.L.; Piotrowski, J. and Slomiany,A. 1999.

Endothelin-1, interleukin-4 and nitric oxide synthase modulators of gastric mucosal injury by indomethacin: Effect of antiulcer agents. J Physiol Pharmacol., 50:197-210.

Soliman, N.A., Zineldeen, D.H., Katary, M.A. and Ali,D.A. 2016.

$\mathrm{N}$-acetylcysteine a possible protector against indomethacin-induced peptic ulcer: crosstalk between antioxidant, anti-inflammatory, and antiapoptotic mechanisms. Can $J$ Physiol Pharmacol.,14: 1-8.

Tripp, M.A. and Tepperman,B.L. 1995.

Effect of nitric oxide on integrity, blood flow and cyclic GMP levels in the rat gastric mucosa: modulation by sialo adenectomy. Br. J. Pharmacol., 115(2):344 -348.

Velasco-Lezama, R., Tapia-Aguilar, R., Rom'an-Ramos, R., Vega-Avila, E. and P'erezGuti'errez, S. 2006.

Effect of Plantago major on cell proliferation in vitro.J. Ethnopharm., 103:36-42.

Yesilda E., Sezik E., Fujita T., Tanaka S. and Tabata, M. 1993.

Screening of some Turkish medicinal plants for their antiulcer genic activities. Phytother Res., 7: $263-265$ 


\section{Eman M. et al}

التأثير الوقائي لمستخلص لسان الحمل على قرحة المعده المُحدثه بواسطة الإندميثاسين في الفئران

\section{إيمان محمود راغب ، إيمان سامي ابراهيم ، رشا علاء الدين شلبي}

$$
\text { المركز الإقليمي للأغذيه والأعلاف ـ مركز البحوث الزراعيه ــ الجيزه ــ مصر }
$$

قرحة المعدة تعتبر من أخطر الأمراض عالمياً. يالرغم من وجود العديد من الأدويه المستخدمه لعلاج

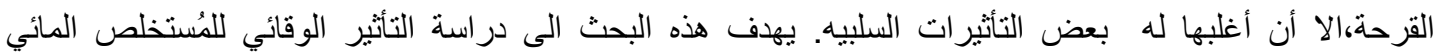

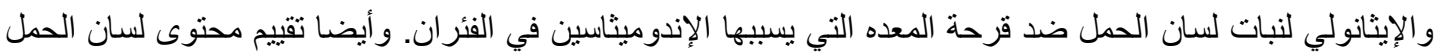

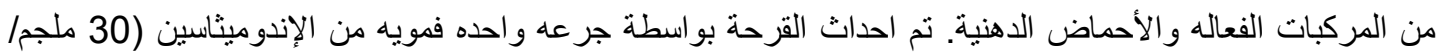

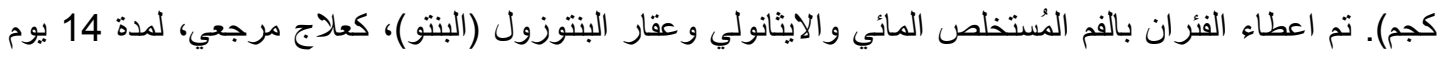

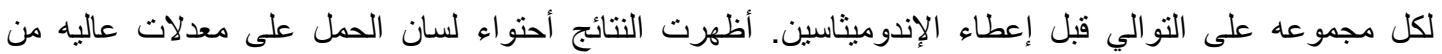

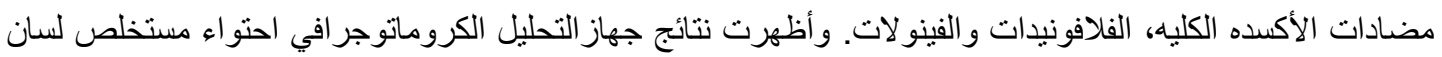
الحمل على نسبة عالية من حمض اللينوليك (33,79\%)، حض الأوليك (29,41\%)، وحمض الباليك

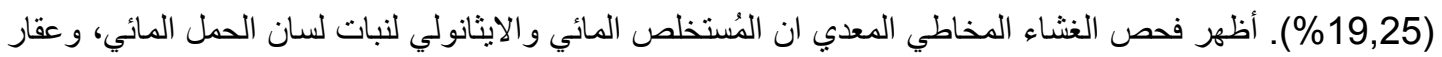

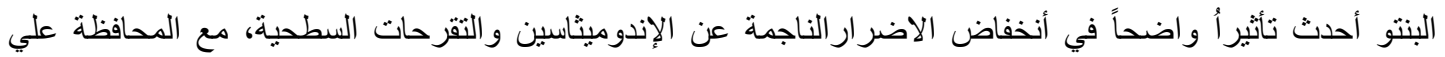

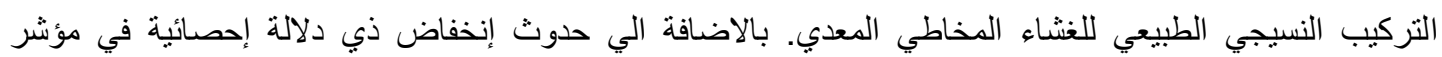

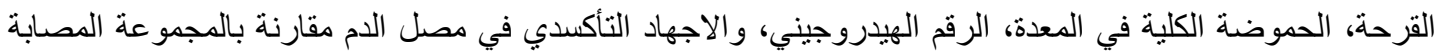

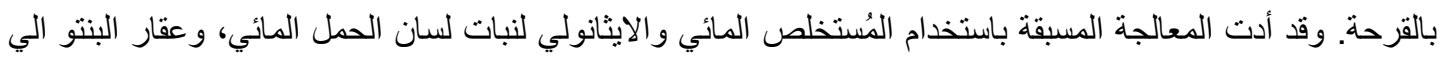

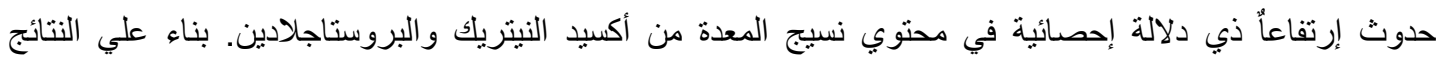

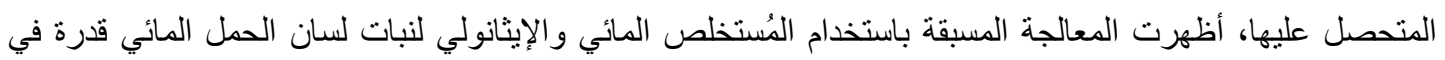

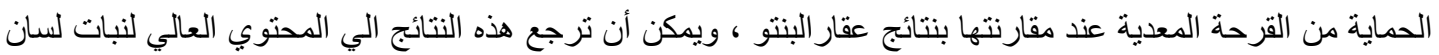
الحمل من المواد الفعالة النشطة التي لها خصائص مضاد مناده للأكسدة. 